\title{
KOMUNITAS ASCIDIA DI PESISIR MALALAYANG DUA, TELUK MANADO, SULAWESI UTARA
}

\author{
(Ascidian Community In the Coastal area of Malalayang Dua, Manado \\ Bay, North Sulawesi)
}

Adrianus Malintoi ${ }^{1}$, Inneke F. M. Rumengan ${ }^{1}$, Kakaskasen A. Roeroe ${ }^{1}$, Veibe Warouw ${ }^{1}$, Ari B. Rondonuwu², Medy Ompi ${ }^{*}$

${ }^{1}$ Program Studi IImu Kelautan, FPIK Unsrat Manado.

${ }^{2}$ Program Studi Manajemen Sumberdaya Perairan, FPIK Unsrat Manado

*Corresponding author: ompimedy@unsrat.ac.id

\begin{abstract}
Abstrack
Field survey on ascidian community was conducted along the coastal area of Malalayang Dua in order to find out species of ascidia, species abundance, and ascidian substrates. A survey method and quadrant transects were applied. Pictures were taken, while species and their substrates were sampled. Species identification was based on morphological characteristics, while substrate type identification was based on ascidian species attachment. The results shows that 21 ascidian species were found in the the coastal of Malalayang Dua. Didemnum molle was the highest abundant species in the area, followed by Polycarpa aurata, Polycarpa sp.4. and Polycarpa sp.2. . Dead coral algaes (DCA) were found to be the most preferred substrates by ascidians in the area.
\end{abstract}

Keywords : ascidia, species, substrate, distribution, and abundance

\section{Abstrak}

Survei lapangan terhadap komunitas ascidia dilakukan di pesisir Malalayang Dua untuk mendapatkan data jenis, kelimpahan, dan substrat ascidia. Metode yang digunakan yaitu metode survei jelajah dan transek kuadran. Identifikasi jenis ascidia dilakukan berdasarkan karakteristik morfologi. Hasil penelitian ditemukan ada 21 jenis ascidia. Substrat jenis death coral algae (DCA) merupakan substrat yang paling banyak ditempati ascidia. Kelimpahan ascidia tertinggi adalah Didemnum molle di pesisir Malalayang Dua, diikuti oleh Polycarpa aurata, Polycarpa sp.4. dan Polycarpa sp.2. Death coral alga (DCA) ditemukan sebagai substrat yang paling disukai oleh ascidia di daerah itu.

Kata Kunci : ascidia, spesies, substrat, distribusi, dan kelimpahan

\section{PENDAHULUAN}

Keanekaragaman biota laut yang tinggi, termasuk komunitas Ascidia yang tergolong pada Filum Chordata, Sub-filum Tunikata (Urochordata) dan Kelas Ascidiacea. Ascidiacea merupakan kelas yang paling beragam spesiesnya, sekitar 3000 spesies yang sudah dideskripsikan menghuni wilayah laut dari perairan dangkal hingga perairan dalam. Informasi ini dapat diakses pada Ascidiacea World Database (Shenkar et al., 2020).
Golongan ascidia merupakan salah satu biota penyusun terumbu karang yang terkenal karena bersimbiosis dengan mikroba yang menghasilkan beragam senyawa bioaktif (Chen et al., 2018). Keberadaan ascidia cukup unik kerena organisme ini ditemukan dengan berbagai bentuk, warna, dan ukuran yang beragam pada berbagai jenis substrat, seperti yang ditemukan di perairan Sulawesi Utara (Kuberlaborbir, 2010). Namun berapa banyak jenis ascidia, kelimpahan dari setiap jenis dan substrat apa saja yang 
menjadi tempat penempelan ascidia belum dilaporkan. Tulisan ini memaparkan hasil penelitian terkait aspek-aspek tersebut, khususnya yang ditemukan di Pantai Malalayang Dua Teluk Manado, Sulawesi Utara.

\section{METODE PENELITIAN}

Penelitian dilakukan pada bulan April sampai Oktober 2019 berlokasi di Pesisir Malalayang Dua, Teluk Manado, Sulawesi Utara, pada posisi geografis $1^{\circ} 27^{\prime} 40$. 69” $\mathrm{N}, 124^{\circ} 47^{\prime} 30.20^{\prime \prime} \mathrm{E}$. seperti yang dapat dilihat pada Gambar 1 .
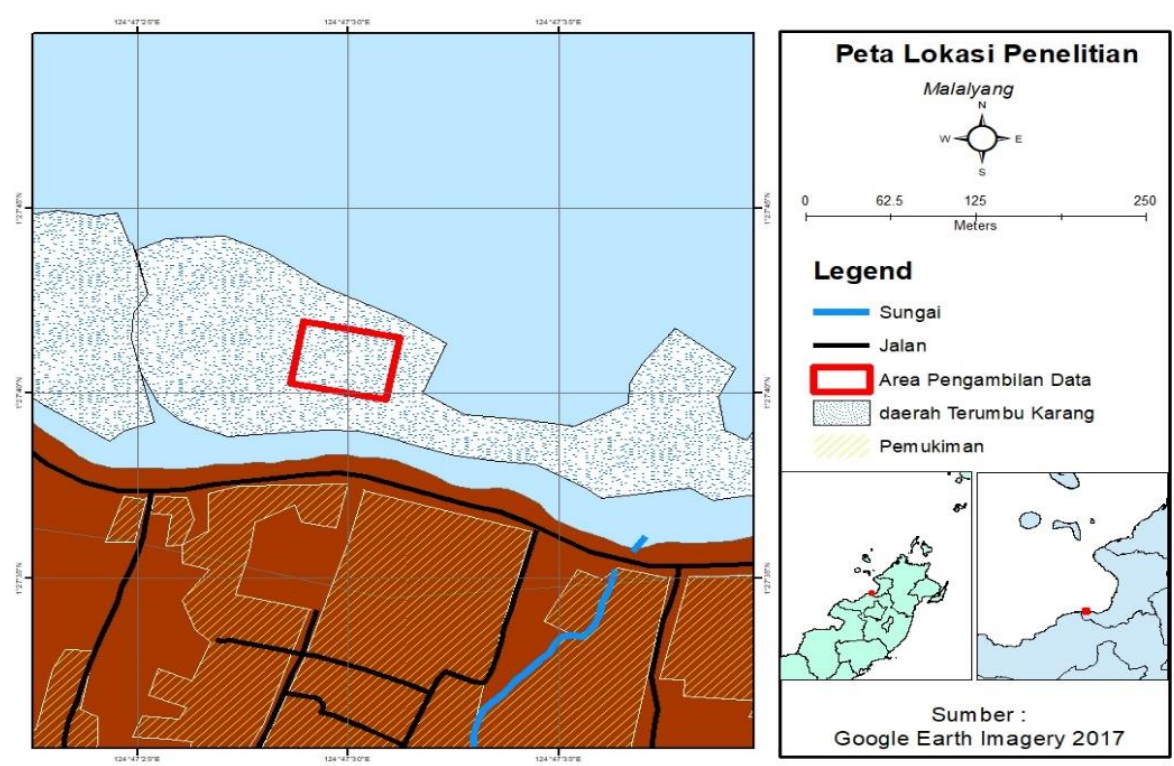

Gambar 1. Lokasi penelitian di Pesisir Malalayang Dua, Teluk Manado, Sulawesi Utara.

Pengambilan data ascidia dilakukan dengan menyelam menggunakan alat SCUBA dilakukan dengan dua metode, yaitu Metode Survey Jelajah (Ontorael, dkk., 2012) dan Metode Transek Kuadran (Ompi, dkk., 2019) yang telah dimodifikasi. Penyelaman pertama menggunakan dengan Metode Survey Jelajah untuk mengamati jenis-jenis ascidia dan melihat substrat yang ditempati ascidia. Survei dengan Metode Transek Kuadran (Ompi, dkk., 2019), dilakukan untuk memperoleh data kelimpahan setiap jenis ascidia. Adapun cara kerja dari dua metode ini ialah sebagai berikut :

a) Metode Survei Jelajah

Penyelam turun bersamaan dan langsung mencari lokasi yang terdapat ascidia. Penyelaman dilakukan pada kedalaman 3 - $12 \mathrm{~m}$. Penyelam melakukan survei di sepanjang jarak $50 \mathrm{~m}$ sejajar garis pantai, yang di mulai atau titik awal pada kedalaman $12 \mathrm{~m}$, kemudian ke arah pantai yang lebih dangkal sampai pada kedalaman $3 \mathrm{~m}$, sambil mengamati ada tidaknya ascidia. Penyelam mencari ascidia pada daerah terumbu dengan melihat karakteristik morfologi secara umum dan dengan bantuan gambar ascidia yang di bawah. Setiap ascidia yang ditemukan, diidentifikasi langsung berdasarkan morfologi. Pengamatan dilakukan terhadap jenis ascidia dan tipe substrat yang ditempati dan didokumentasi.

b) Metode Transek Kuadran

Penyelam turun pada lokasi penyelaman pertama, di mana ditemukan ascidia. Kuadran dengan ukuran $25 \times 25$ $\mathrm{cm}^{2}$ yang terbuat dari pipa plastik dan yang sudah dimodifikasi. Penyelam menarik meteran secara vertikal, dari arah darat ke laut sepanjang jarak $50 \mathrm{~m}$. Pada bagian ujung, tengah, dan pangkal meteran diikat pemberat agar meteran tidak mengambang.

Perhitungan mulai dilakukan dari arah darat ke laut. Kuadran diletakkan dari titik nol dengan interval tiap kuadran sejauh 5 $\mathrm{m}$. Setiap kuadran di foto tegak lurus dari atas dengan jarak yang konsisten antara 
kamera dan kuadran. Setelah itu dilakukan tahap identifikasi jenis dan jumlah ascidia yang terdapat di dalam kuadran. Identifikasi dilakukan di laboratorium berdasarkan hasil gambar yang diambil dilapangan.

Parameter lingkungan yang diukur adalah suhu, salinitas, kecerahan, dan $\mathrm{pH}$. Suhu dan kecerahan diukur langsung di lapangan, sedangkan salinitas dan $\mathrm{pH}$ air laut diukur di laboratorium Biologi Molekuler dan Farmasitika Laut FPIK Unsrat.

Identifikasi dilakukan dengan melihat karakterisitik morfologi ascidia yaitu warna, ukuran dan bentuk tubuh secara umum. Jenis substrat diidentifikasi berdasarkan jenis substrat yang ditempati ascidia. Identifikasi jenis dilakukan dengan bantuan buku Tropical Pacific Invertebrates (Colin \& Arneson, 1995) dan Gittenberger (2007).

\section{HASIL DAN PEMBAHASAN}

Pantai Malalayang Dua sering menjadi destinasi wisata bawah air bagi turis lokal dan mancanegara. Komponen dasar perairan Malalayang Dua, terdiri dari daerah terumbu karang, ada juga terumbu karang buatan, dan substrat berpasir. karang buatan. Dari hasil penelitian yang dilakukan ditemukan ada 5 famili, 9 genus, dan 21 jenis ascidia. Untuk lebih jelas mengenai jenis-jenis ascidia tersebut, dapat dilihat pada Tabel 1.

Tabel 1. Jenis-jenis ascidia yang ditemukan di Perairan Malalayang Dua

Family Genus Jenis Ascidia

\begin{tabular}{|c|c|c|}
\hline Styelidae & Polycarpa & Polycarpa aurata (Quoy \& Gaimard, 1834) \\
\hline Styelidae & Polycarpa & Polycarpa sp 1 . Heller, 1877 \\
\hline Styelidae & Polycarpa & Polycarpa sp 2. (Posp19PM-2) \\
\hline Styelidae & Polycarpa & Polycarpa sp 3. (Posp19PM-3) \\
\hline Styelidae & Polycarpa & Polycarpa sp 4. (Posp19PM-4) \\
\hline Styelidae & Polycarpa & Polycarpa contecta (Sluiter, 1904) \\
\hline Didemnidae & Lissoclinum & Lissoclinum patella (Gottschaldt, 1898) \\
\hline Didemnidae & Lissoclinum & Lissoclinum bistratum (Sluiter, 1905) \\
\hline Didemnidae & Didemnum & Didemnum molle (Herdman, 1886) \\
\hline Didemnidae & Didemnum & Didemnum membranaceum Sluiter, 1909 \\
\hline Didemnidae & Didemnum & Didemnum $\mathrm{sp}_{1}$. Savigny, 1816 \\
\hline Didemnidae & Didemnum & Didemnum sp. $_{2 .}$ (Disp19PM-2) \\
\hline Didemnidae & Diplosoma & Diplosoma virens (Hartmeyer, 1909) \\
\hline Didemnidae & Diplosoma & Diplosoma simile (Sluiter, 1909) \\
\hline Didemnidae & Atriolum & Atriolum robustum Kott, 1983 \\
\hline Diazonidae & Rhopalea & Rhopalea sp. Philippi, 1843 \\
\hline Diazonidae & Rhopalea & Rhopalea crassa (Herdman, 1880) \\
\hline Ascidiidae & Phallusia & Phallusia julinea Sluiter, 1915 \\
\hline Ascidiidae & Phallusia & Phallusia arabica Savigny, 1816 \\
\hline Ascidiidae & Eudistoma & Eudistoma reginum Kott, 1990 \\
\hline Clavelinidae & Oxycornia & Oxycorynia fascularis Drasche, 1882 \\
\hline
\end{tabular}

a) Polycarpa aurata (Quoy \& Gaimard, 1834)

$P$. aurata merupakan jenis yang paling banyak ditemukan di wilayah Pasifik.
Tunik berwarna kuning atau oranye dengan garis ungu menjadi warna yang menonjol dari jenis ini. Jenis ini ditemukan 
di daerah terumbu, khususnya pada karang mati yang ditumbuhi alga.

b) Polycarpa $\mathrm{sp}_{1}$. Heller, 1877

Jenis ini dapat menampilkan bentuk tubuh untuk beradapatasi terhadap kondisi lingkungannya yang berbedabeda (Colin \& Arneson, 1995). Polycarpa $\mathrm{sp}_{1}$. berwarna coklat gelap yang menyerupai lingkungan tempat ascidia ini menempel.

c) Polycarpa sp 2. (Posp19PM-2)

Polycarpa $\mathrm{sp}_{2}$. berwarna coklat keabuabuan yang sudah ditutupi oleh proses sedimentasi. Substrat yang ditempati Polycarpa $\mathrm{sp}_{2}$. merupakan DCA. Pada saat survei dilapangan, Polycarpa $\mathrm{sp}_{2}$. ditemukan menjadi substrat bagi ascidia lain, yaitu L. patella.

\section{d) Polycarpa sp 3 . (Posp19PM-3)}

Polycarpa $\mathrm{sp}_{3}$. ditemukan dengan bagian luar tubuh berwarna coklat. Warna coklat ini merupakan warna dari alga yang menempel. Sedangkan, lingkaran lubang berwarna merah muda.

e) Polycarpa sp4. (Posp19PM-4)

Polycarpa $\mathrm{sp}_{4}$. yang ditemukan memiliki warna coklat pucat. Bagian dalam tubuh yang diamati memiliki warna putih dan pada bagian tubuh incurrent siphon to mouth berbentuk seperti simbol tambah.

\section{f) Polycarpa contecta}

Jenis ini membentuk kelompok padat individu soliter (Colin \& Arneson, 1995). P. contecta berwarna coklat terang dan terlihat seperti substrat yang ditempati.

g) Lissoclinum patella (Gottschaldt, 1898)

L. patella merupakan golongan ascidia berukuran tubuh besar. Ciri-ciri khas dari L. patella adalah berkoloni tunggal, berwarna hijau keabu-abuan, Warna hijau pada L. patella merupakan adanya mikroba simbion yang berasosiasi. Spesies ini biasanya hidup menempel pada celahcelah karang.

h) Lissoclinum bistratum (Sluiter, 1905)

L. bistratum hidup berkoloni, tunik berwarna hijau dengan ukuran tubuh yang kecil. Warna hijau dihasilkan oleh adanya mikroba simbion.

i) Didemnum molle (Herdman, 1886)

$D$. molle merupakan jenis yang paling banyak ditemukan di daerah terumbu. Ciriciri umum yang dapat dilihat dari jenis ini yaitu hidup berkoloni, berbentuk bulat, menempel pada satu tempat dalam jumlah yang banyak.

j) Didemnum membranaceum Sluiter, 1909

D. membranaceum memiliki ciri bukaan tunik seperti tikar. Tunik $D$. membranaceum memiliki warna dominan merah muda dengan garis putih.

k) Didemnum $\mathrm{sp}_{1}$ Savigny, 1816

Didemnum $\mathrm{sp}_{1}$. memiliki tunik berwarna merah muda, hidup berkoloni, dan menempel pada susbstrat keras.

I) Didemnum $\mathrm{sp}_{2 .}$ (Disp19PM-2)

Didemnum $\mathrm{sp}_{2}$. ditemukan menempel pada bebatuan karang yang sudah ditumbuhi alga. Jenis ini terlihat mencolok dengan warna tunik hitam dan putih.

m) Diplosoma virens (Hartmeyer, 1909)

$D$. virens merupakan jenis yang berwarna hijau, yang merupakan warna dari ganggang yang bersimbion dengannya (Colin \& Arneson, 1995). $D$. virens ditemukan menempel pada substrat yang keras.

n) Diplosoma simile (Sluiter, 1909)

D. simile menempel substrat keras pada karang yang sudah mati. Tunik berwarna hijau mengandung mikroba simbion Prochloron sp. (Kuberlaborbir, 2010).

o) Atriolum robustum Kott, 1983

A. robustum ditemukan hidup berkoloni. Jenis ini memiliki tunik dominan berwarna putih dan sedikit hijau pada bagian mulut. Tunik memiliki lubanglubang kecil dan berisi pigmen merah yang tertutup dengan mikroba simbion berwarna hijau yang diketahui sebagai Prochloron sp. 
p) Rhopalea sp. Philippi, 1843

Warna biru yang transparan merupakan ciri khas dari jenis ini. Rhopalea sp. ditemukan menempel pada pinggiran bebatuan/terumbu.

q) Rhopalea crassa (Herdman, 1880)

Ini adalah salah satu jenis ascidia yang paling indah diantara ascidia lain. Tubuh dari $R$. crassa yang terlihat transparan membuat spesies ini mudah terlihat diantara terumbu. $R$. crassa biasanya ditemukan menempel pada daerah terumbu dengan substrat keras.

r) Phallusia julinea Sluiter, 1915

Jenis ini memiliki warna yang khas yaitu kuning terang. Warna kuning berasal dari sel darah berpigmen (Colin \& Arneson, 1995).

s) Phallusia arabica Savigny, 1816

$P$. arabica berwarna putih bening.

Pada saat penelitian di perairan
Malalayang, $P$. arabica ditemukan pada kedalaman $9 \mathrm{~m}$ dan menempel pada substrat DCA.

t) Eudistoma reginum Kott, 1990

E. reginum merupakan jenis dari famili Polycitoridae. E. reginum memiliki warna coklat gelap dengan bentuk tubuh yang rata.

u) Oxycorynia fascularis Drasche, 1882

$O$. fascularis memilii bentuk tubuh yang unik, yaitu bulatan kecil yang banyak pada ujung tangkai. Pada setiap bulatan tersebut, terdapat sifon dengan warna lingkaran putih. $O$. fascularis biasanya ditemukan menempel di daerah terumbu karang. Tunik berwarna hijau gelap sampai abu-abu dengan berwarna putih pada lingkaran sifon.

Untuk lebih jelasnya mengenai jenisjenis ascidia yang teridentifikasi di pesisir Malalayang Dua, dapat dilihat pada Gambar 2.
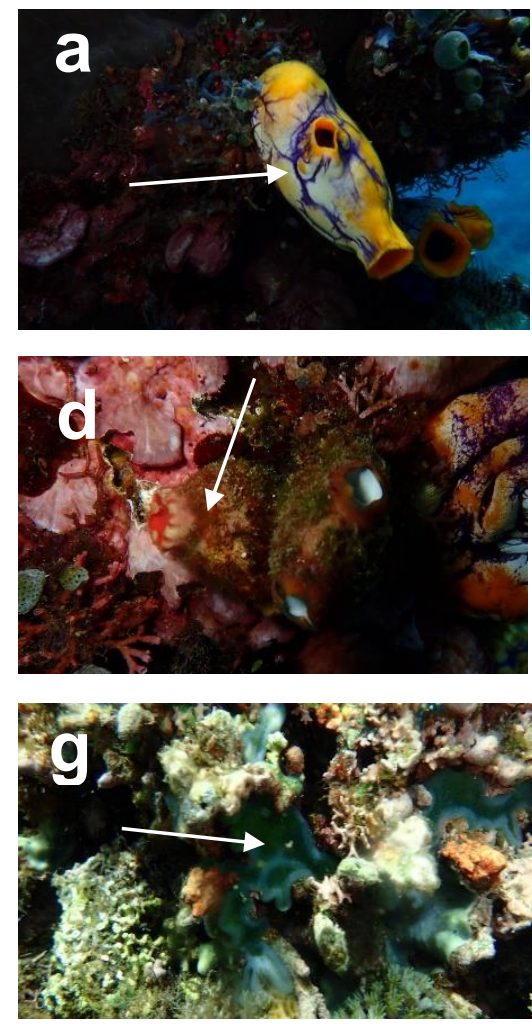
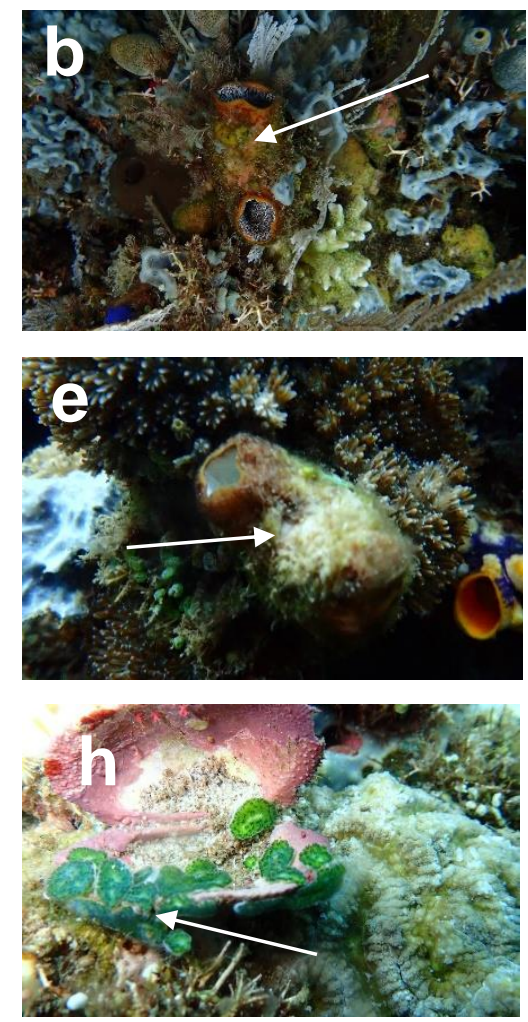
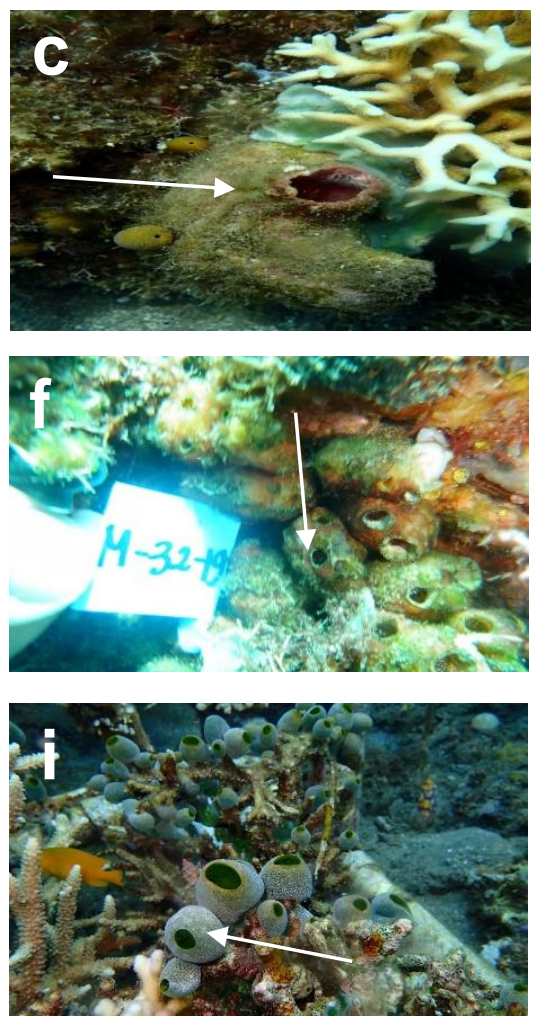

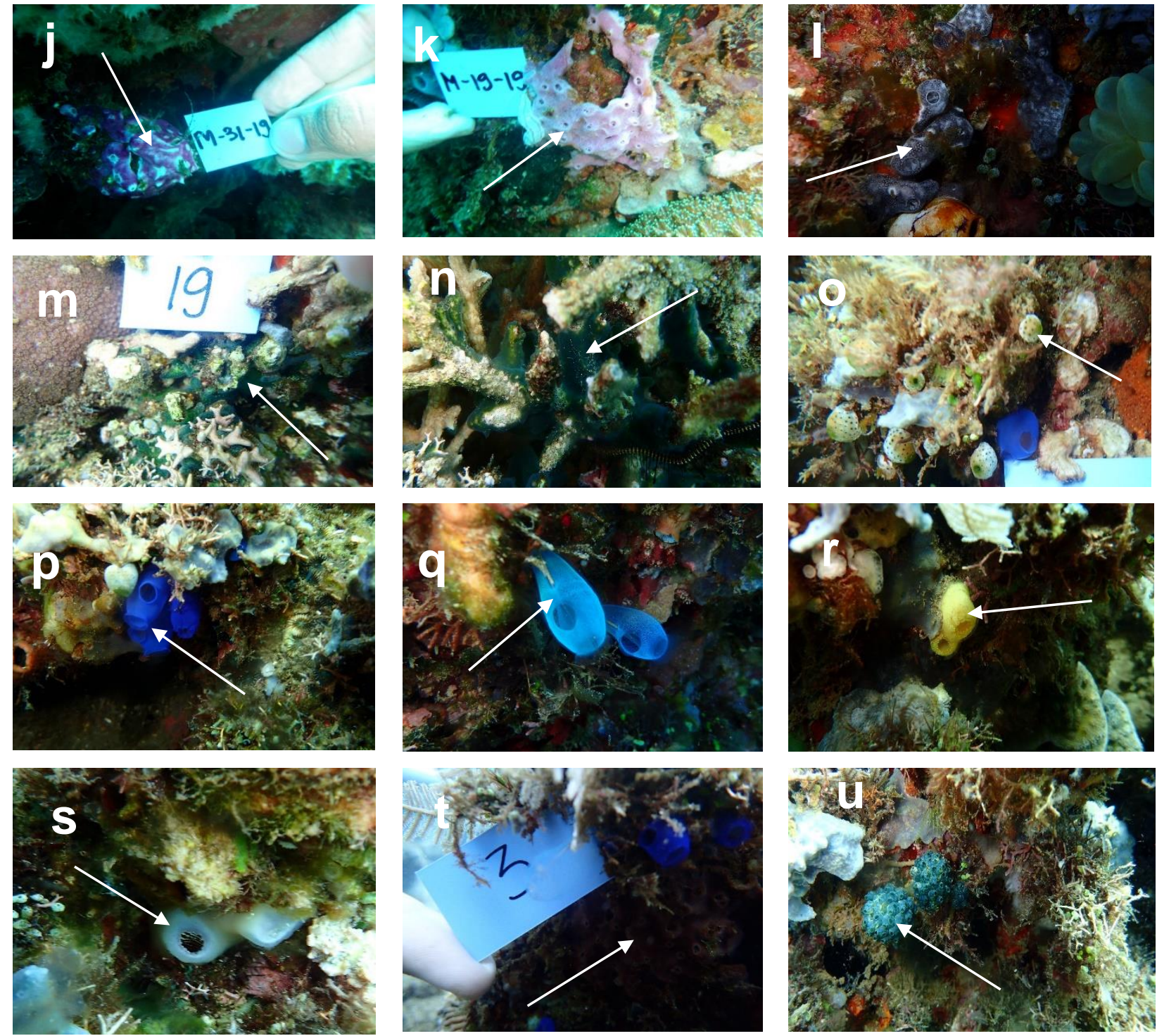

Gambar 2. Ascidia yang ditemukan di Perairan Malalayang Dua, Teluk Manado, Sulawesi Utara. (a) P. aurata; (b) Polycarpa $\mathrm{sp}_{1 .}$; (c) Polycarpa $\mathrm{sp}_{2 .}$; (d) Polycarpa $\mathrm{sp}_{3}$; (e) Polycarpa sp 4 ; ; (f) P. contecta; (g) L. patella; (h) L. bistratum; (i) D. molle; (j) D. membranaceum; (k) Didemnum $\mathrm{sp}_{1}$; (l) Didemnum $\mathrm{sp}_{2}$; (m) D. virens; (n) D. simile; (o) A. robustum; (p) Rhopalea sp.; (q) R. crassa; (r) P. julinea; (s) $P$. arabica; (t) E. reginum; (u) O. fascularis.

Jenis-jenis ascidia yang ditemukan di Pesisir Malalayang Dua pada di tahun 2019 ada yang sama tapi ada juga yang berbeda dengan yang ditemukan oleh Kuberlaborbir (2010). Kuberlaborbir (2010) melakukan penelitian menggunakan metode survei jelajah dengan menyelam bebas (free dive). Ada 28 jenis ascidia yang tergolong dalam 7 famili yang ditemukan oleh Kuberlaborbir (2010). Dalam penelitian ini, ada 21 jenis, yang tergolong dalam 5 famili yaitu Didemnidae, Styelidae, Clavelinidae, Diazonidae, dan
Ascidiidae yang teridentifikasi dalam penelitian ini.

Ada 10 jenis ascidia yang ditemukan dalam penelitian ini sama jumlah jenisnya seperti yang ditemukan oleh Kuberlaborbir (2010). Ke 10 jenis yang dimaksud adalah berikut : $P$. aurata, $L$. patella, L. bistratum, $O$. fascularis, $D$. molle, D. membranaceum, Didemnum $\mathrm{sp}_{1 .}$, $D$. virens, $R$. crassa, dan $P$. julinea.

Ada 11 jenis ascidia yang tidak ditemukan oleh Kuberlaborbir (2010), yang baru teridentifikasi di pesisir Malalayang Dua dalam penelitian ini di tahun ini, 2019, 
yaitu: Polycarpa $\mathrm{sp}_{1 .}$., Polycarpa $\mathrm{sp}_{2 .}$ Polycarpa $\mathrm{sp}_{3 .,}$ Polycarpa $\mathrm{sp}_{4 .,}$ Didemnum $\mathrm{sp}_{2 .}$, D. simile, A. robustum, Rhopalea sp., $P$. arabica, E. reginum, dan $P$. contecta. Ada 18 jenis ascidia yang teridentifikasi di Tahun 2010, tetapi tidak teridentifikasi dalam penelitian ini di tahun 2019.

Ada banyak faktor yang menyebabkan adanya perbedaan jenis, dimana biota avertebrata dasar laut ditemukan, salah satunya adalah substrat, waktu, dan ruang (Ompi et al 2019), dimana faktor-faktor ini dapat menyebabkan adanya variasi jenis seperti yang dilaporkan oleh Kuberlaborbir (2010) dan jenis-jenis ascidia yang ditemukan dalam penelitian ini. Ada 5 jenis substrat yang teridentifikasi sebagai tempat tinggal jenis-jenis biota ini Jenis substrat DCA merupakan substrat yang dominan ditempati oleh ascidia. Ada 14 jenis ditemukan menempati substrat tersebut, yaitu $P$. aurata, Polycarpa $\mathrm{sp}_{1}$, Polycarpa $\mathrm{sp}_{2}$, Polycarpa $\mathrm{sp}_{3}, \quad O$. fascularis, $D$. membranaceum, A.robustum, Rhopalea sp., $R$. crassa, $P$. julinea, E. reginum, Didiemnum $\mathrm{sp}_{2 .}, \quad P$. arabica, dan $P$. contecta. Substrat CB menempati urutan terbanyak kedua yang ditempati oleh Polycarpa $\mathrm{sp}_{4}$., D.molle, D. virens, dan D.simile. L. patella menempel pada substrat CM, Didemnum $\mathrm{sp}_{1 .}$, pada DC dan L. bistratum pada CKM.

Penempelan ataupun pemilihan substrat nampak berawal dari saat biota ini berada di fase akhir larva. Umumnya biota avertebrata dasar laut (Ompi \& Svane 2018), termasuk ascidia, fase akhir larva akan memilih substrat kesukaan untuk menempel, selanjutnya biota ini akan menetap, cenderung tidak berpindah, selanjutnya bertumbuh menjadi individu dewasa, dan memasuki siklus reproduksi selanjutnya.

Aktivitas manusia seperti parawisata di sekitar lokasi penelitian, dapat menyebabkan sebagai salah satu faktor yang dapat pula mempengaruhi kehadiran jenis-jenis ascidia, dalam hal ini rendahnya jenis-jenis ascidia yang menempati pesisir Malalayang Dua dibandingkan dengan daerah lainnya, seperti yang dilaporkan oleh Kuberlaborbir (2010).
Kelimpahan ascidia teridentifikasi bervariasi untuk tiap jenis, $D$. molle memiliki kelimpahan rata-rata 2,09/25 $\mathrm{cm}^{2}$. $P$. aurata memiliki kelimpahan rata-rata terbanyak kedua, yaitu $0,27 / 25 \mathrm{~cm}^{2}$. Polycarpa $\mathrm{sp}_{4}$. dan Polycarpa $\mathrm{sp}_{2}$. memiliki rata-rata kelimpahan yang sama, yaitu $0,09 / 25 \mathrm{~cm}^{2}$.

Kemudian, hasil pengukuran parameter lingkungan dapat dilihat pada Tabel 2, di mana faktor-faktor lingkungan ini nampak berada pada kondisi yang ditolelir (Mawaleda 2014), sekaligus menunjang kehidupan ascidia di daerah ini.

Tabel 2. Hasil pengukuran parameter lingkungan

\begin{tabular}{cc}
\hline Parameter Lingkungan & Nilai \\
\hline Suhu & $29^{\circ} \mathrm{C}$ \\
$\mathrm{pH}$ & 7 \\
Salinitas & $36 \%$ o \\
Kecerahan & 12 meter \\
\hline
\end{tabular}

\section{PENUTUP \\ Kesimpulan}

Dari hasil penelitian, ditemukan 21 jenis ascidia yang ada di Pesisir Malalayang Dua. Substrat yang ditempati adalah coral branching (CB), death coral algae (DCA), death coral (DC), coral masive (CM), dan cangkang moluska (CKM), dimana karang mati yang ditutupi oleh alga menjadi substrat favorit dari ascidia di lokasi pesisir Malalayang Dua. D. molle memiliki kelimpahan tertinggi dibandingkan dengan jenis lainnya di Pesisir Malalayang Dua.

\section{DAFTAR PUSTAKA}

Chen, L., Hu, J.S., Xu, J.L., Shao, C.L. and Wang, G.Y., 2018. Biological and chemical diversity of ascidianassociated microorganisms. Marine drugs, 16(10), p.362.

Colin P. L., Arneson C. 1995. Tropical Pacific Invertebrates. A Field Guide to the Marine Invertebrates Occurring on Tropical Pacific Coral Reefs, Seagrass Beds and Mangroves. Coral Reef Press. California. Hal. 267-287. 
Gittenberger A. (2007). The Dutch Ascidians Homepage by Arjan Gttenberger. Diunggah pada 15 Agustus 2019 dari http://www.ascidians.com.

Kubelaborbir, T. M. 2010. Inventarisasi dan Karakterisasi Ascidiacea di Perairan Pantai Malalayang Sulawesi Utara dan Identifikasi Molekular Prochloron sp. Yang Berasosiasi Dengan Ascidiacea. Tesis. Tidak Dipublikasikan. FPIK Universitas Sam Ratulangi, Manado.

Ompi P.M., Boneka F. B., Ompi M., Rimper J. R. T. S. L., Roeroe K. A., dan Kambey A. D. 2019. Kelimpahan, Distribusi, dan Keanekaragaman Nudibranchia di Nudifall dan Nudiretreat Selat Lembeh, Sulawesi Utara. Jurnal Pesisir dan Laut Tropis, $7(2)$.

Ompi M.., Lumoindong F., Undap N., Papu A., Wägele H. 2019. Monitoring marine Heterobranchia in Lembeh Strait, North Sulawesi (Indonesia), in a changing environment. AACL Bioflux 12(2):664-677.
Ompi M., Svane I., 2018 Comparing spawning, larval development, and recruitments of four mussel species (Bivalvia: Mytilidae) from South Australia. AACL Bioflux 11(3):576588.

Ontorael R., Wantasen., Rondonuwu A. B. 2012. Kondisi Ekologi Dan Pemanfaatan Sumberdaya Mangrove Di Desa Tarohan Selatan Kecamatan Beo Selatan Kabupaten Kepulauan Talaud. Jurnal IImiah Platax. I(1).hal.8 Shenkar N., Gittenberger A., Lambert G., Rius M., Moreira da Rocha R., Swalla B.J., Turon X. (2020). Ascidiacea World Database. Accessed at http://www.marinespecies.org/ascidia cea on 2020-01-15. doi: 10. $14284 / 353$. 